\title{
Кафиев И.Р., Галлямова Л.Р. \\ Фильтросимметрирующие устройства для снижения влияния несиммметрии напряжения источника питания на надежность линейного асинхронного двигателя
}

Башкирский государственный аграрный университет (Россия, Уфа)

doi: $10.18411 / l j-31-01-2018-52$

idsp: 000001:lj-31-01-2018-52

\section{Аннотация}

В статье проведён краткий обзор фильтросимметрирующих устройств, применяемых для снижения влияния несимметрии напряжения источника питания на надежность работы линейного асинхронного двигателя. Рассмотрены основные достоинства и недостатки этих устройств.

Ключевые слова: линейный асинхронный двигатель; надежность; несимметрия напряжения; фильтросимметрирующее устройство; срок службы.

Для обеспечения нормальных условий работы линейных асинхронных двигателей (ЛАД), применяемых в приводах технологических машин агропромышленного комплекса, необходимо питание их электроэнергией, параметры которой соответствуют определенным требованиям к ее качеству. Несимметрия токов в сети вызывает несимметрию напряжений на зажимах трехфазных электроприемников, что приводит к сокращению срока службы ЛАД [1].

Для снижения уровня несимметрии токов и напряжений разработаны различные по сложности, трудоемкости и затратам способы и устройства. При невозможности обеспечить требуемый уровень несимметрии напряжений с помощью схемных решений (рациональным распределением нагрузок), применяют специальные фильтросимметрирующие устройства (ФСУ).

ФСУ выполняются неуправляемыми или управляемыми в зависимости от особенностей графика нагрузки. Они представляют установки на основе пассивных элементов (конденсаторов и катушек индуктивности), работающие в несимметричном режиме и установки на основе схемы Штейнмеца и её модификаций [2].

ФСУ на основе конденсаторной установки состоит из конденсаторных батарей с несимметрично распределенными емкостями по фазам, коммутационной аппаратуры и системы управления. Данные устройства обладают симметрирующим эффектом за счет управления коммутационной аппаратурой, позволяющей подключать конденсаторные батареи на работу в несимметричном режиме (рисунок 1) [2]. Устройства рекомендуется устанавливать для двух- и трехфазных нагрузок с более низким коэффициентом мощности.

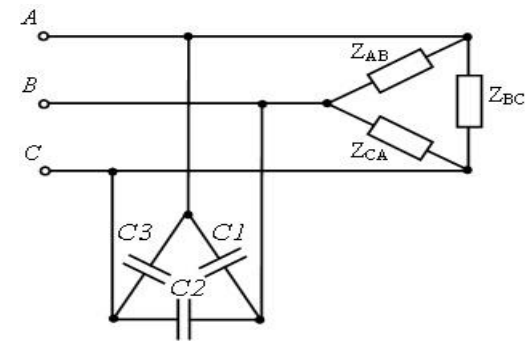

Рисунок 1 ФСУ на конденсаторных батареях

ФСУ на основе конденсаторных батарей имеет следующие недостатки:

- при их подключении к сети происходит скачок тока, поэтому в установке следует использовать специальные контакторы (пускатели); 
- существенно усложняется управление при симметрировании;

- невозможность обеспечения высокой точности компенсации и плавного регулирования в связи со ступенчатым подключением конденсаторных батарей;

- при симметрировании дополнительно генерируется реактивная мощность;

- подключение таких ФСУ вызывает нежелательные переходные процессы в электроэнергетической системе - возможно появление резонансных контуров.

Схема Штейнмеца (рисунок 2) обеспечивает снижение несимметрии токов, которые вызываются при питании однофазной нагрузки линейным напряжением [3] .

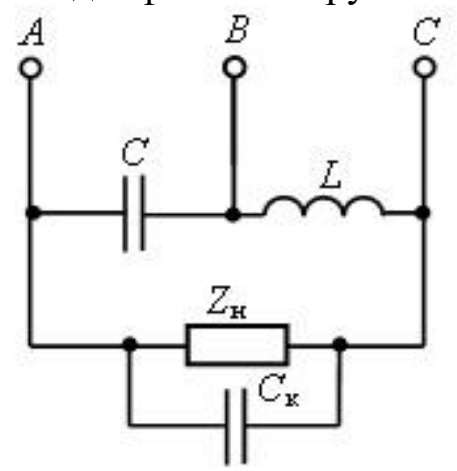

Рисунок 2 ФСУ на основе схемы Штейнмеца

ФСУ на основе схемы Штейнметца наиболее эффективно при коэффициенте мощности нагрузки, равном единице. Поэтому при активно-индуктивной нагрузке параллельно ей подключается дополнительный корректирующий элемент - конденсатор Ск для компенсации индуктивной реактивной мощности.

Недостатками ФСУ на основе схемы Штейнмеца являются [4]:

- невозможность бесконтактного управления ёмкостью без увеличения (до $173 \%$ мощности нагрузки) мощности ФСУ;

- недостаточное использование мощности применяемых для симметрирования элементов (коэффициент использования равен 0,866);

- сложность регулирования данных устройств;

- наличие двух разных по характеру нагрузки регулируемых элементов.

Есть разработки симметрирующих устройств, основанных на схеме Штейнмеца, которые значительно снижают установленные мощности ФСУ и дают возможность автоматического поддерживания режима симметрии с помощью лишь одной индуктивности, которая регулируется бесконтактно, например подмагничиванием [4]. Примером такого устройства является схема с дросселем-делителем (рисунок 3 ).

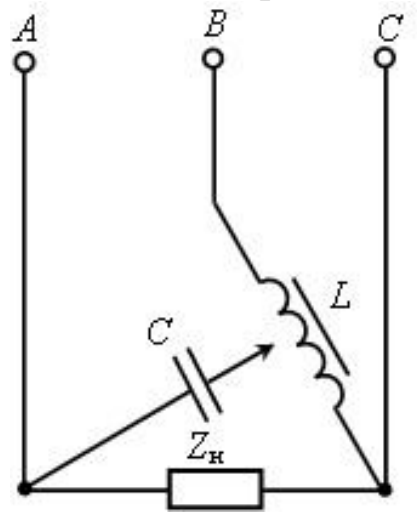

Рисунок 3 ФСУ на основе схемы Штейнмеиа с дросселем-делителем 
Таким образом, симметрирование пассивными элементами имеет множество недостатков. Такие установки находят применение для конкретных установок с постоянным графиком нагрузки.

1. Кафиев И.Р., Галлямова Л. Р. К вопросу о надежности линейного асинхронного двигателя // Наука и образование: новое время. 2017. № 5 (22). С. 256-259.

2. Управление качеством электроэнергии: учебное пособие для вузов / И.И. Карташев, В.Н. Тульский, Р.Г. Шамонов, Ю.В. Шаров, А.Ю. Воробьев; под ред. Ю.В. Шарова. 2-е изд., перераб. и доп. М.: Издательский дом МЭИ, 2008. 354 с.

3. Шидловский А.К. Кузнецов В.Г. Повышение качества энергии в электрических сетях // АН УССР,ин-т электродинамики. Киев: Научная мысль, 1985. 268 с.

4. Повышение эффективности использования электроэнергии в системах электротехнологии / Борисов Б.П., Вагин Г.Я., Лоскутов А.Б., Шидловский А.К.// АН УССР, ин-т электродинамики. Киев: Научная мысль, 1990. 240 с.

\section{Клименко С.В. ${ }^{1}$, Тихомиров Д.А. ${ }^{2}$ \\ Применение УФ и ИК- излучения для пастеризации молока в тонкопленочной установке \\ ${ }^{1}$ ФББУ ВО Российский государственный агроинженерный заочный университет \\ (Россия, Балашиха) \\ ${ }^{2}$ ФГБНУ «Федеральный научный агроинженерный цеентр ВИМ» \\ (Россия, Москва)}

doi: 10.18411/lj-31-01-2018-53

idsp: 000001:lj-31-01-2018-53

К числу широко распространенных и энергоемких процессов первичной обработки жидких пищевых продуктов относится термообработка с целью их консервации. При этом ставится задача максимального сохранения питательных и вкусовых качеств продукта. Наиболее эффективным и доступным способом воздействия на микрофлору молока в условиях животноводческих ферм является пастеризация [1].

Для кратковременной пастеризации используют непрерывно действующие паровые барабанные пастеризаторы с давлением пара до 0,04 МПа. Выпускаются установки пастеризационно-трубчатые, а также пастеризационно-охладительные пластинчатые. Применяются также ванны длительной пастеризации. В таких аппаратах, помимо высоких энергозатрат, неизбежен перегрев жидкости, так как только часть ее соприкасается с греющей стенкой, а остальная масса подогревается за счет турбулизации.

Известен метод «холодной» пастеризации с помощью УФ-излучения актинизация. Основные его преимущества заключаются в снижении энергозатрат, малом времени (2-3 с) обработки молока, низкой девитаминизации, увеличении содержания витамина D в молоке. Однако, при дозах УФ-излучения обеспечивающих необходимый уровень обеззараживания, наблюдаются изменение вкуса и свойств молока $[2,3]$.

Целью проводимых исследований стало обоснование параметров и режимов работы комбинированной установки при воздействии УФ и ИК- излучения на свойства молока, для уменьшения бактериальной обсемененности до $3 \cdot 105 \mathrm{KOE} / \mathrm{cm} 3$ и снижения общего расхода энергии.

Особенности ИК- излучения заключаются в том, что при передаче теплоты нагреваемому продукту можно создать плотность теплового потока на обрабатываемой поверхности больше, чем при конвективном или контактном нагреве. Это обеспечивает высокую интенсивность технологического процесса. ИК- излучение проникает на некоторую глубину, что исключает чрезмерный перегрев и нежелательные изменения в поверхностном слое материала.

Наиболее целесообразно ИК- облучением осуществлять поверхностный или сквозной нагрев продукта небольшой толщины [4]. 